\title{
Telemedicine Coding and Reimbursement - Current and Future Trends
}

\author{
Fariha Abbasi-Feinberg, MD
}

\section{KEYWORDS}

- Telehealth codes $\bullet$ Telehealth reimbursement $\bullet$ Medicare telehealth $\bullet$ CPT telehealth codes

- Remote physiologic monitoring codes $\bullet$ Online digital evaluation codes $\bullet$ Telehealth legislation

- Non-face-to-face services

\section{KEY POINTS}

- Innovation in technology is redefining the world, including health care. Patients want convenient and quality interactions with their providers.

- The addition of telemedicine technologies and asynchronous provider-to-patient communications is creating a more connected model of health care that will improve access and the value of care while decreasing costs, as well as enabling patients to participate more directly in their own care.

- As new technologies and new models of care continue to emerge, providers need to continue to monitor the rapidly changing landscape of telemedicine coding and reimbursement.

- Telehealth coding and reimbursement rules are payor and state dependent.

Sleep disturbances affect an estimated $35 \%$ to $40 \%$ of the adult population in the United States. Approximately 5.9 million US adults have been diagnosed with obstructive sleep apnea, but 23.5 million Americans remain undiagnosed. ${ }^{1}$ Among older adults, the prevalence of insomnia disorder, defined as difficulty initiating or maintaining sleep with daytime impairment, ranges from $25 \%$ to $40 \%$. $^{2}$ Untreated insomnia and obstructive sleep apnea are associated with increased health care use and costs. ${ }^{3}$

Health care costs in the United States accounted for $17.8 \%$ of the gross domestic product in 2019. The US Centers for Medicare and Medicaid Services (CMS) projects that health care spending will reach $20 \%$ of gross domestic product by $2025 .{ }^{4}$ Despite this financial outlay, the health outcome goals have not been achieved.
This failure may be attributable to a fragmented health care system as well as lack of access to care. The United States health care system has a serious workforce supply problem. The Association of American Medical Colleges (AAMC) projects that physician demand will continue to grow faster than supply, leading to a projected total physician shortfall by 2030 of between 40,800 and 104,900 physicians. ${ }^{5}$ This shortfall includes sleep medicine specialists. Lack of access to care and cost of health care are leading to innovative models, including the growth of telehealth services. Sleep medicine is a technology-dense specialty and is poised to be active in telemedicine. ${ }^{6,7}$

Government and private payers appreciate the potential cost savings that are achievable through telemedicine. Medicare's focus on value-based

This article was accepted before the COVID-19 pandemic. Many of the coding guideline requirements have been temporarily suspended beginning March 6, 2020, and lasting through the national public health emergency as declared by the Secretary of Health and Human Services. Please see addendum for details. It is unclear at the time of this final submission how long these changes will stay in effect. Millennium Physician Group, 13813 Metro Parkway, Fort Myers, FL 33912, USA

E-mail address: fabbasifeinberg@gmail.com 
care models has seen a significant shift from volume to value and led to an expansion of coverage for telemedicine-based services. The health care industry has realized that remote monitoring programs can be involved in chronic disease management and may be suitable for some acute medical scenarios as well. Many employer-based plans are contracting directly with physician groups to obtain health care that is convenient and efficient for the employees. The global telehealth market, which in 2016 was valued at $\$ 2.78$ billion, is projected to reach $\$ 9.35$ billion by 2021 , growing at a compound annual growth rate of $27.5 \% .^{8}$

This excitement involving telemedicine is dampened by questions concerning reimbursement. Navigating issues regarding telehealth/telemedicine policy, coding, and reimbursement is complicated. CMS started reimbursing for telemedicine services in 1999 for some patients in rural areas but with significant limitations. Over the last few years there has been substantial expansion of coverage from CMS as well as commercial payors. This last year, 2019, has been active for telehealth legislation along with acceptance of new Current Procedural Terminology (CPT) codes. ${ }^{9}$ There are slated changes coming in 2021 for Evaluation and Management (E/M) coding, along with new updates in remote patient monitoring and chronic care management guidelines. This article focuses on the CPT codes most pertinent to the practice of sleep medicine. Although every attempt is made to be accurate at the time of this writing, readers should understand that this is not a comprehensive list. Reviewing coding and reimbursement issues is an evolving situation and it is recommended that readers try to verify the most updated policies.

For the purpose of this analysis, telehealth coding and reimbursement has been divided into distinct categories (Fig. 1):

$$
\begin{aligned}
& \text { Medicare fee for service } \\
& \text { Medicare advantage } \\
& \text { Medicaid } \\
& \text { Private payors } \\
& \text { Employer pay } \\
& \text { Self-pay }
\end{aligned}
$$

This articles review all these potential models of reimbursement with a focus on Medicare coding as the starting point. Whether these codes can be used by readers depends on the various payors, with Medicare having the strictest guidelines. Although readers may not meet all the Medicare rules for coding and reimbursement, many of the other entities described earlier allow these codes to be used for telehealth services.

\section{DEFINITIONS}

The terms telehealth and telemedicine are often used interchangeably. Telemedicine is usually defined as "the remote diagnosis and treatment of patients by means of telecommunication technology." 10 The Telehealth Resource Center defines telehealth as a "collection of means of methods for enhancing health care, public health and health education delivery and support using telecommunication technologies." 11 Telehealth is not a specific clinical service and is a more inclusive term for the wide collection of applications in the field. Telehealth may involve not only providers but also ancillary staff and health educators. Another term often heard is digital health, which includes categories such mobile health, health information technology wearable devices, telehealth, and telemedicine, as well as personalized medicine.

Table 1 provides some clarification of terms frequently used in this area of medicine. CMS defines telemedicine as live, interactive audiovisual transmission of a physician or other qualified health care provider (QHCP) from one site to another using telecommunication technology. There are detailed recommendations regarding the originating site, the distant site, and codes that can be billed. Asynchronous telemedicine, also known as store and forward, is only reimbursed by Medicare in certain states (Alaska and Hawaii) for specific situations.

\section{MEDICARE}

In almost all cases, Medicare only reimburses for live telemedicine interactions. The idea is to keep the contact similar to an in-person face-to-face visit. The Social Security Act governs which telemedicine services are and are not covered under Medicare. There are certain restrictions regarding eligible health care providers, and the locations of patients and services covered (Table 2).

The originating site must be located within a Health Professional Shortage Area or a county outside of a metropolitan statistical area. The Health Resources and Services Administration and the Census Bureau determine the eligibility ${ }^{12}$ (https://data.hrsa.gov/tools/medicare/telehealth).

Patients need to be at 1 of 10 qualifying originating sites. Service is provided by 1 of 8 qualifying providers.

Technology is real time and face to face, and the service is among the list of CPT/Healthcare Common Procedure Coding System (HCPCS) ${ }^{13}$ codes that are covered (CPT is Copyright 2019 American Medical Association. All rights reserved. CPT is a 


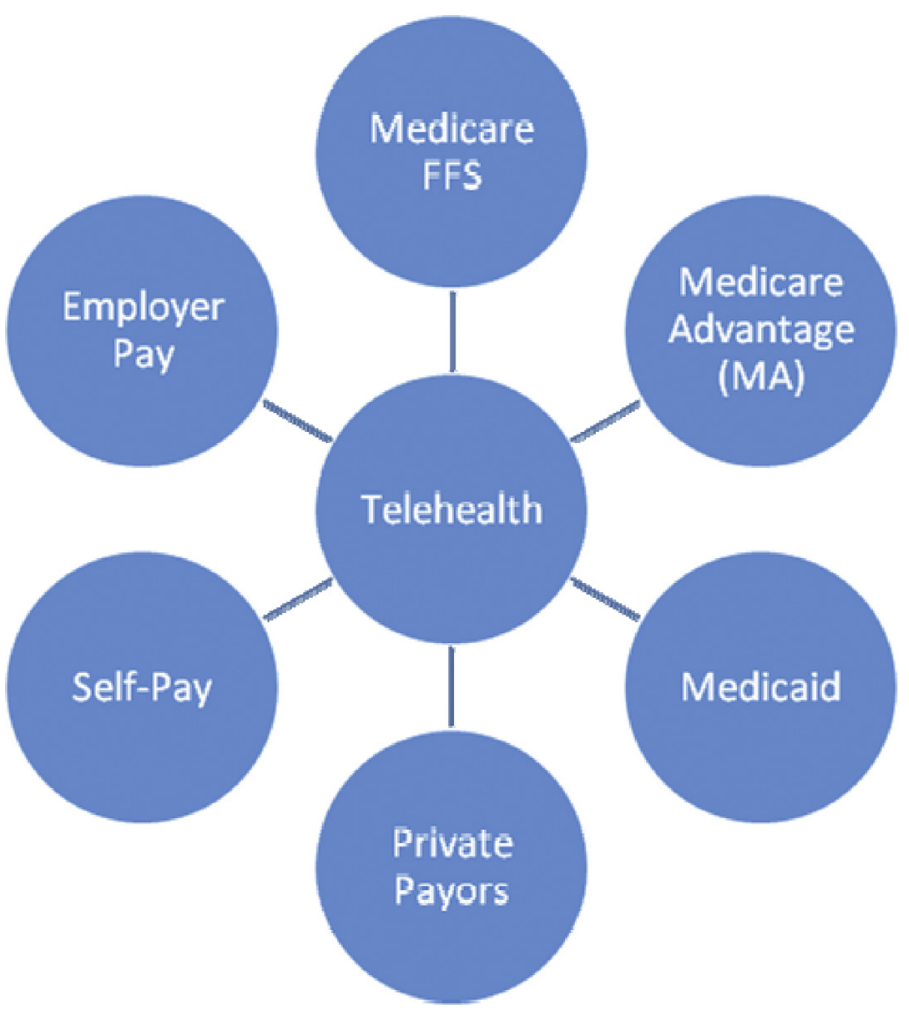

Fig. 1. Categories for telehealth coding and reimbursement. FFS, fee for service.

\begin{tabular}{ll}
$\begin{array}{l}\text { Table 1 } \\
\text { Definitions }\end{array}$ & $\begin{array}{l}\text { Telemedicine services are live, interactive audio and } \\
\text { visual transmissions of a physician-patient encounter } \\
\text { from one site to another using telecommunication } \\
\text { technology }\end{array}$ \\
\hline Telemedicine (synchronous) & $\begin{array}{l}\text { The location of the physician or other qualified health } \\
\text { care professional at the time the service is being } \\
\text { furnished via telecommunication technology }\end{array}$ \\
\hline Originating site & $\begin{array}{l}\text { The location of a patient at the time the service is being } \\
\text { furnished via a telecommunication system }\end{array}$ \\
\hline Physician or Other Qualified & $\begin{array}{l}\text { Per CPT, a physician or other qualified health care } \\
\text { professional is an individual who is qualified by } \\
\text { Health Care Provider } \\
\text { education, training, licensure/regulation, and facility } \\
\text { privileging who performs a professional service } \\
\text { within their scope of practice and reports that } \\
\text { professional service }\end{array}$ \\
\hline $\begin{array}{l}\text { Medical information is stored and forwarded to be } \\
\text { reviewed by a physician or health care practitioner at } \\
\text { a distant site. The medical information is reviewed } \\
\text { without the patient being present. Also referred to } \\
\text { as store-and-forward telehealth or noninteractive } \\
\text { telecommunication }\end{array}$ \\
\hline
\end{tabular}




\begin{tabular}{|c|c|}
\hline Location (Qualifying Rural) & Qualifying Providers \\
\hline Physician or practitioner offices & Physicians \\
\hline Hospitals & Nurse practitioners \\
\hline Critical access hospitals & Physician assistants \\
\hline Rural health clinics & Nurse midwives \\
\hline Federally qualified health centers & Clinical nurse specialist \\
\hline $\begin{array}{l}\text { Hospital-based or critical access } \\
\text { hospital--based renal dialysis center }\end{array}$ & Certified registered nurse anesthetists \\
\hline Skilled nursing facilities & Clinical psychologist and sociologist \\
\hline Community mental health centers & Registered dieticians or nutrition professionals \\
\hline Mobile stroke units & - \\
\hline $\begin{array}{l}\text { Homes of patients with end-stage } \\
\text { renal disease receiving home dialysis }\end{array}$ & - \\
\hline
\end{tabular}

registered trademark of the American Medical Association.) All the following codes can be found in the appropriate code books.

\section{CURRENT PROCEDURAL TERMINOLOGY CODES FOR TELEMEDICINE}

CMS recognizes and reimburses for certain CPT codes along with modifiers (Table 3 ). These codes include E/M codes as well as eligible CPT codes listed in the CPT manual.

Place of service (POS) is usually listed as 02 -Telehealth: the location where health services and health-related services are provided or received, through a telecommunication system.

(Note: This telehealth POS code does not apply to originating site facilities billing a facility fee.)

\section{EVALUATION AND MANAGEMENT CODING FOR 2021}

On November 1, 2019, CMS approved the Medicare physician fee schedule for 2020. This schedule includes a historic change in the way physicians have been coding patient encounters for the last 25 years. These revisions to the E/M office visit CPT code changes will be effective January 1, 2021 and, because they will affect how physicians code for telemedicine $\mathrm{E} / \mathrm{M}$ visits as well, the codes will be reviewed. Further changes may be described when the physician fee schedule is published for 2021 , in the fall of 2020.

Summary of changes: ${ }^{14,15}$

1. Eliminate history and physical as elements for code selection. Providers need to perform a medically appropriate history and/or physical examination, which will contribute to the time spent with the patient as well as the medical decision making, but these "bullets" will not determine appropriate code level.

2. Documentation can be based on either medical decision making (MDM) or total time (TT)

a. MDM uses the current CMS Table of Risk as groundwork for the new elements of MDM with some clarifications, including redefining some current concepts and data elements

\section{Table 3 \\ Modifiers}

\section{Modifier}

GT

$\mathrm{GQ}$

95

G0

\section{Description}

Via interactive audio and video telecommunications systems

Via asynchronous telecommunications systems

Synchronous telemedicine service rendered via a real-time interactive audio and video telecommunications system (reported only with codes from Appendix P of CPT manual)

Telehealth services for diagnosis, evaluation, or treatment of symptoms of an acute stroke 
to focus on task for management of the patients (Table 4).

b. $T$ is the total minimum time the provider spends on date of service. This total includes non-face-to-face time, such as reviewing the chart, documentation, and care coordination (Table 5).

3. CPT code 99201 will be deleted, leaving 4 levels of new patient E/M codes but continuing with 5 levels of coding for established patients.

4. New add-on code for extended office visit time CPT code 99XXX and a new complexity add on code GPC1X.

Changes in terminology contrasted to familiar language (Table 6).

"Number of Diagnoses or Management Options" will become "Number and Complexity of Problems Addressed"

"Amount and/or Complexity of Data to be Reviewed" will become "Amount and/or Complexity of Data to be Reviewed and Analyzed"

"Risk of Complications and/or Morbidity or Mortality" will become "Risk of Complications and/or Morbidity or Mortality of Patient Management."

These E/M codes can be used for appropriate telemedicine visits with modifiers.

As an example, a patient is evaluated from the primary care physician's office in a rural setting as a follow-up visit for obstructive sleep apnea. The provider is at a distant site and performs appropriate follow-up visit for level 3 coding requirements. The provider would submit code 99213-GT. The originating site would also bill for a facility fee for hosting the patient (HCPCS code Q3014).

Medicare will reimburse the telemedicine service at the current fee schedule rate for the comparable in-person medical service.

\section{MEDICARE-COVERED TECHNOLOGY-BASED SERVICES}

Telemedicine policies are set by Congress with updates to the Social Security Act. A bill must be introduced and approved by both the House of Representatives and the Senate and signed into law by the President. This process occurs extremely slowly, if at all. Therefore, Medicare regulations for telemedicine are slow to change. Because of technological advancements, updates are essential. CMS has approved other options for various non-face-to face services that are covered and do not require any changes in legislation. These codes are included under the physician fee schedule and are updated on an annual basis. For 2020 , the conversion factor is $\$ 36.89$. Work relative value units (RVUs) are not specifically covered in this review because they change on a yearly basis. CMS offers a free search tool for RVUs for every CPT code, as well as a jointly maintained site for HCPCS codes (https://www.cms. gov/apps/physician-fee-schedule/licenseagreement.aspx, https://hcpcs.codes/search/).

\section{NON-FACE-TO-FACE SERVICES Online Digital Evaluation and Management Services}

Online Digital Evaluation and Management Services are new additions to CPT inspired by new digital communication tools such as patient portals. These codes allow health care professionals to more efficiently connect with patients at home and exchange information. These new codes report online digital evaluation services or e-visits. These codes are patient initiated and are asynchronous. Consent is required from patients on an annual basis.

CPT 99421, 99422, and 99423 are patientinitiated services with physician or other qualified health care professionals (QHPs). These services require evaluation, assessment, and management

\begin{tabular}{lllll}
\hline $\begin{array}{l}\text { Table } \mathbf{4} \\
\text { Documentation for time or medical decision making }\end{array}$ & \multicolumn{2}{c}{ MDM } \\
\hline Present & $\begin{array}{c}\text { Typical } \\
\text { face-to-face } \\
\text { time }\end{array}$ & $\begin{array}{c}\text { Number of } \\
\text { diagnosis or } \\
\text { management } \\
\text { options }\end{array}$ & $\begin{array}{c}\text { Amount and complexity } \\
\text { of data to be reviewed }\end{array}$ & $\begin{array}{c}\text { Risk of complications } \\
\text { and/or morbidity } \\
\text { or mortality }\end{array}$ \\
\hline 2021 & $\begin{array}{c}\text { TT on day of } \\
\text { encounter }\end{array}$ & $\begin{array}{c}\text { Number and } \\
\text { complexity } \\
\text { of problems } \\
\text { addressed }\end{array}$ & $\begin{array}{c}\text { Number and complexity } \\
\text { of problems to be } \\
\text { addressed }\end{array}$ & $\begin{array}{c}\text { Risk of complications } \\
\text { and/or morbidity/ } \\
\text { mortality of patient } \\
\text { management }\end{array}$ \\
\hline
\end{tabular}




\begin{tabular}{|lll|}
\hline $\begin{array}{l}\text { Table } 5 \\
\text { Time for coding }\end{array}$ & \\
E/M Code & $\begin{array}{l}\text { Current } \\
\text { Time (min) }\end{array}$ & $\begin{array}{l}\text { Time in } \\
\text { 2021 (min) }\end{array}$ \\
\hline 99202 & 20 & $15-29$ \\
\hline 99203 & 30 & $30-44$ \\
\hline 99204 & 45 & $45-59$ \\
\hline 99205 & 60 & $60-74$ \\
\hline 99211 & 5 & NA \\
\hline 99212 & 10 & $10-19$ \\
\hline 99213 & 15 & $20-29$ \\
\hline 99214 & 25 & $30-39$ \\
\hline 99215 & 40 & $40-54$ \\
\hline
\end{tabular}

Abbreviation: NA, not applicable.

of the patients. They are not for communicating test results, scheduling appointments, and so forth. Each patient is an established patient and these services are initiated through a HIPPA (Health Insurance Portability and Accountability Act)-compliant platform. This service can occur over a period of 7 days and includes cumulative time to review records or data, develop a management plan, and communicate back to the patient. Online digital E/M services require a permanent document of the encounter and are performed by individuals who can bill for E/M services. They may not be used for work done by clinical staff.
CPT 99421: online digital E/M service for an established patient.

- Reported once for the cumulative time over a 7-day period

- Time includes review of the inquiry, review of records or data, and subsequent communication with the patient

- If a separately reported $\mathrm{E} / \mathrm{M}$ visit occurs within the 7-day period, the time or complexity can be added to the reported $\mathrm{E} / \mathrm{M}$ code

- From 5 to 10 minutes

CPT 99422: as above, 11 to 20 minutes

CPT 99243: as above, 21 or more minutes

The CPT editorial panel finalized similar codes for qualified nonphysician health care professionals (98970-98972), but these are not recognized by CMS. CMS has approved some G codes that can be used by qualified nonphysician health care providers, such as physical therapists, occupational therapists, social workers, dieticians, and speech therapists.

G2061: qualified nonphysician health care professional online assessment for an established patient

- Reported once for the cumulative time during the 7 days

- From 5 to 10 minutes

G2062: as above, for 11 to 20 minutes

G2063: as above, for 21 minutes or more

Table 6

Changes in terminology

\begin{tabular}{|c|c|c|c|c|}
\hline Code & $\begin{array}{l}\text { Level of } \\
\text { MDM ( } 2 \text { out } 3 \text { ) }\end{array}$ & $\begin{array}{l}\text { Number and } \\
\text { Complexity of } \\
\text { Problems } \\
\text { Addressed } \\
\end{array}$ & $\begin{array}{l}\text { Amount and/or } \\
\text { Complexity of Data } \\
\text { to be Reviewed and } \\
\text { Analyzed }\end{array}$ & $\begin{array}{l}\text { Risk of Complications } \\
\text { and/or Morbidity or } \\
\text { Mortality of Patient } \\
\text { Management }\end{array}$ \\
\hline 99211 & NA & NA & NA & NA \\
\hline $\begin{array}{l}99202 \\
99212\end{array}$ & Straightforward & Minimal & Minimal or none & $\begin{array}{l}\text { Minimal risk of morbidity } \\
\text { from additional } \\
\text { diagnostic testing } \\
\text { or treatment } \\
\end{array}$ \\
\hline $\begin{array}{l}99203 \\
99213\end{array}$ & Low & Low & Limited & $\begin{array}{l}\text { Low risk of morbidity } \\
\text { from additional } \\
\text { diagnostic testing } \\
\text { or treatment } \\
\end{array}$ \\
\hline $\begin{array}{l}99204 \\
99214\end{array}$ & Moderate & Moderate & Moderate & $\begin{array}{l}\text { Moderate risk of } \\
\text { morbidity from } \\
\text { additional diagnostic } \\
\text { testing and treatment }\end{array}$ \\
\hline $\begin{array}{l}99205 \\
99215\end{array}$ & High & High & Extensive & $\begin{array}{l}\text { High risk of morbidity } \\
\text { from additional } \\
\text { diagnostic testing } \\
\text { and treatment }\end{array}$ \\
\hline
\end{tabular}




\section{Virtual Care Codes}

Physicians and QHPs can be reimbursed for these virtual check-ins for patients who are not certain whether their problems warrant an in-office visit. If the check-in does not lead to an appointment or is caused by a previous $\mathrm{E} / \mathrm{M}$ visit within the last 7 days, these codes can be billed as a stand-alone service.

\section{HCPCS G2012 virtual check ins}

G2012: brief communication technology-based service (eg, virtual check-in) by a physician or other QHP who can report E/M services.

- Provided to an established patient

- Not originating from a related E/M service provided within the previous 7 days nor leading to an E/M service or procedure within the next 24 hours or soonest available appointment

- From 5 to 10 minutes of medical discussion

- No frequency or location requirements

\section{HCPCS G2010 review of images or video}

G2010: remote evaluation of recorded video and/ or images submitted by an established patient (eg, store and forward).

- Including interpretation with follow-up with the patient within 24 business hours

- Not originating from a related E/M service provided within the previous 7 days nor leading to an E/M service or procedure within the next 24 hours or soonest available appointment

Once again, this can only be for established patients and involves interpretation of recorded images or videos and follow-up in 24 hours. Follow-up can be via phone call, audio/video, secure text, email, or patient portal communication.

\section{DIGITALLY STORED DATA SERVICES/REMOTE PHYSIOLOGIC MONITORING AND TREATMENT MANAGEMENT SERVICES}

These codes are used to report remote physiologic monitoring and treatment management services during a certain time frame. The devices used must be medical devices as defined by the US Food and Drug Administration (FDA) and the service must be ordered by a physician or QHP.

CPT 99457: remote physiologic monitoring treatment management services are provided when clinical staff/physicians/other QHPs use the results of the remote physiologic monitoring to manage a patient under a specific treatment plan
- Twenty minutes of clinical staff (under general supervision), physician, or other QHP time in a calendar month

- Requires live, interactive communication with patient/caregiver during the month

- Can report once every 30 days

CPT 99458: remote physiologic monitoring treatment management services for additional 20 minutes

CPT 99453: initial setup and patient education on use of equipment

CPT 99454: FDA-approved device supply, recording and transmission of data

CPT 99091 was unbundled in 2018.

- This service is defined as collection and interpretation of physiologic data, stored and transmitted by the patient or caregiver to the physician or QHP

- This service requires an initial in-person visit and includes professional time involved with data acquisition, review, and interpretation and modification of care plan

- Including communication to patient or caregiver and appropriate documentation

- Time involved is 30 minutes every 30 days

\section{CARE MANAGEMENT SERVICES}

Sleep physicians may be involved with some of the care management services but probably not frequently. These new codes include Transitional Care Management, Chronic Care Management for 2 or more chronic conditions, as well as Principal Care Management Services for 1 chronic condition, which will most likely be used by specialists.

\section{Principal Care Management Services}

HCPCS G2064: chronic care management services for a single high-risk disease. Thirty minutes of physician or other qualifying health care professional time per calendar month with the following elements: 1 complex condition lasting at least 3 months, which is the focus of the care plan, the condition is of sufficient severity to place patient at risk of hospitalization, or has been the cause of a recent hospitalization; the condition requires development or revision of diseasespecific care plan with frequent adjustments in the medication regimen and or the management of the condition is unusually complex because of comorbidities.

HCPCS G2065: As G2064, 30 minutes of clinical staff time, directed by a physician or other QHP. 


\section{INTERPROFESSIONAL TELEPHONE/INTERNET/ ELECTRONIC HEALTH RECORD CONSULTATIONS (CURRENT PROCEDURAL TERMINOLOGY 99446, 99447, 99448, 99449, 99451, 99452)}

This is an assessment and management service requested by a treating physician or QHP for treatment advice from a physician with specific expertise to assist in the care of a patient without face-to-face contact between the patient and the specialist. This individual may be a new or an established patient with a new problem for the specialist. If this consult leads to a transfer of care, these codes are not reported. These codes include a verbal and written report. The different levels are based on the time of medical discussion and review: 5 to 10 minutes, 11 to 20 minutes, 21 to 30 minutes, or more than 31 minutes.

There is an updated list of covered Medicare telehealth services available at https://www.cms. gov/Medicare/Medicare-General-Information/ Telehealth/Telehealth-Codes.

\section{Medicare Telehealth Changes for 2020 and Beyond}

The Bipartisan Budget Act of 2018 was passed and has expanded stroke telehealth beyond rural areas. It also includes telehealth coverage to home and independent renal dialysis facilities.

The 2018 SUPPORT for Patients and Communities Act requires CMS to adjust their reimbursement policy for telehealth for treating individuals with substance use disorder or co-occurring mental health disorders by removing the geographic requirement for originating sites. This act went into effect January 1, 2020, with bundled-payment and intensity add-on codes.

The movement toward value-based care and reimbursement provides incentives for costefficient practices of care, including the resourceful use of integrated care teams. Alternative payment models, such as those included in Medicare Access and Chip Reauthorization Act of 2015 , offer an opportunity to use telehealth services to meet the needs of providers and patients in this model of care. Certain bundled-payment programs and accountable care organizations are expanding how care is provided. ${ }^{16} \mathrm{CMS}$ continues to reconsider its limited definition of telehealth reimbursable services. The Creating Opportunities Now for Necessary and Effective Care Technologies (CONNECT) for Health Act of 2019 was introduced in the Senate in October 2019. This legislation acknowledges that use of telehealth services for Medicare patients is low. In particular, it notes that health care providers can furnish safe, effective, and high-quality care through telehealth and that barriers to the use of telehealth should be removed. ${ }^{17}$

The American Medical Association has formed a multistakeholder group called the Digital Payment Advisory Group, which is focused on coding and reimbursement issues for telehealth services. ${ }^{18}$

CMS accepts requests for new telehealth codes from any interested party, including medical specialty societies, individual providers, hospital systems, or state and federal agencies. ${ }^{19} \mathrm{New}$ telehealth codes are being added on a regular basis.

\section{MEDICARE ADVANTAGE PROGRAMS AND ACCOUNTABLE CARE ORGANIZATIONS}

Medicare Advantage plans allow private insurers an option to offer plans that are an alternative to traditional Medicare. Thirty-four percent of Medicare recipients are enrolled in a Medicare Advantage program, accounting for coverage of more than 23 million people. ${ }^{20}$ In the past, Medicare Advantage programs could cover telehealth services only per the traditional Medicare guidelines. Section 50323 of the Bipartisan Budget Act of 2018 allowed for a significant change starting 2020 to allow Medicare Advantage programs to include delivery of telehealth services in a plan's basic benefit. It has eliminated the originating site rural restrictions and added patient homes as a qualifying originating site for certain Medicare Advantage plans, as well as accountable care organizations. ${ }^{21}$

This increased flexibility is allowing innovations to promote access to care in a more convenient and cost-effective manner. Many of the plans have developed state-of-the-art technology to ease the process for patients and providers. Most platforms include integration in electronic medical records. It is hoped that the promise of reimbursement for a wider range of telehealth services will encourage organizations to build up their infrastructure as older patients with physical limitations and lack of transport choose virtual visits as part of their health care.

Coding and reimbursement will be the same as in person, along with the modifiers.

\section{MEDICAID}

Medicaid is not tied to Medicare requirements. Each state has specific definitions and requirements. Telemedicine is viewed as a cost-effective alternative to the more traditional face-to-face way of providing medical care (eg, face-to-face consultations or examinations between provider 
and patient) that states can choose to cover. This definition is modeled on Medicare's definition of telehealth services (42 CFR 410.78). Note that the federal Medicaid statute does not recognize telemedicine as a distinct service..$^{22}$

States are constantly updating and refining the policies. All 50 states have policies to allow and reimburse for certain Medicaid telehealth services.

The Center for Connected Health Policy (https:// www.cchpca.org) has an up-to date Web site that monitors changes. At present, remote patient monitoring is available in about half of the states. Fewer states reimburse for asynchronous telemedicine (store and forward) but trends are in favor of these technologies. ${ }^{23}$

In contrast with Medicare policies, about 14 states allow the home as an eligible originating site and 16 states allow schools as an originating site (Fig. 2).

Medicaid reimbursement for specific states is unique. Particular questions to review include which services are covered, list of eligible providers, appropriate CPT codes, location restrictions for patient or provider, and whether a preexisting relationship is required between the patient and provider (https://www. americantelemed.org/; https://www.medicaid. gov/medicaid/benefits/telemedicine/index.html).

\section{COMMERCIAL PAYORS}

Telehealth laws for commercial payors can be divided in 2 categories. Coverage laws define whether a certain code is covered for a member. This contract is between the commercial payor and the consumer. Parity laws are between the health care plans and the providers. ${ }^{24}$ These laws are independent contracts that define the reimbursement for services provided. Parity state laws require commercial payers to reimburse telehealth services the same way as in-person services (Fig. 3).

At the time of this writing, only 8 states do not have parity laws. ${ }^{25}$ Ideally, both coverage and parity laws are required for an effective telehealth program.

The guidelines vary by state and payor and are constantly shifting as new policies are enacted. If
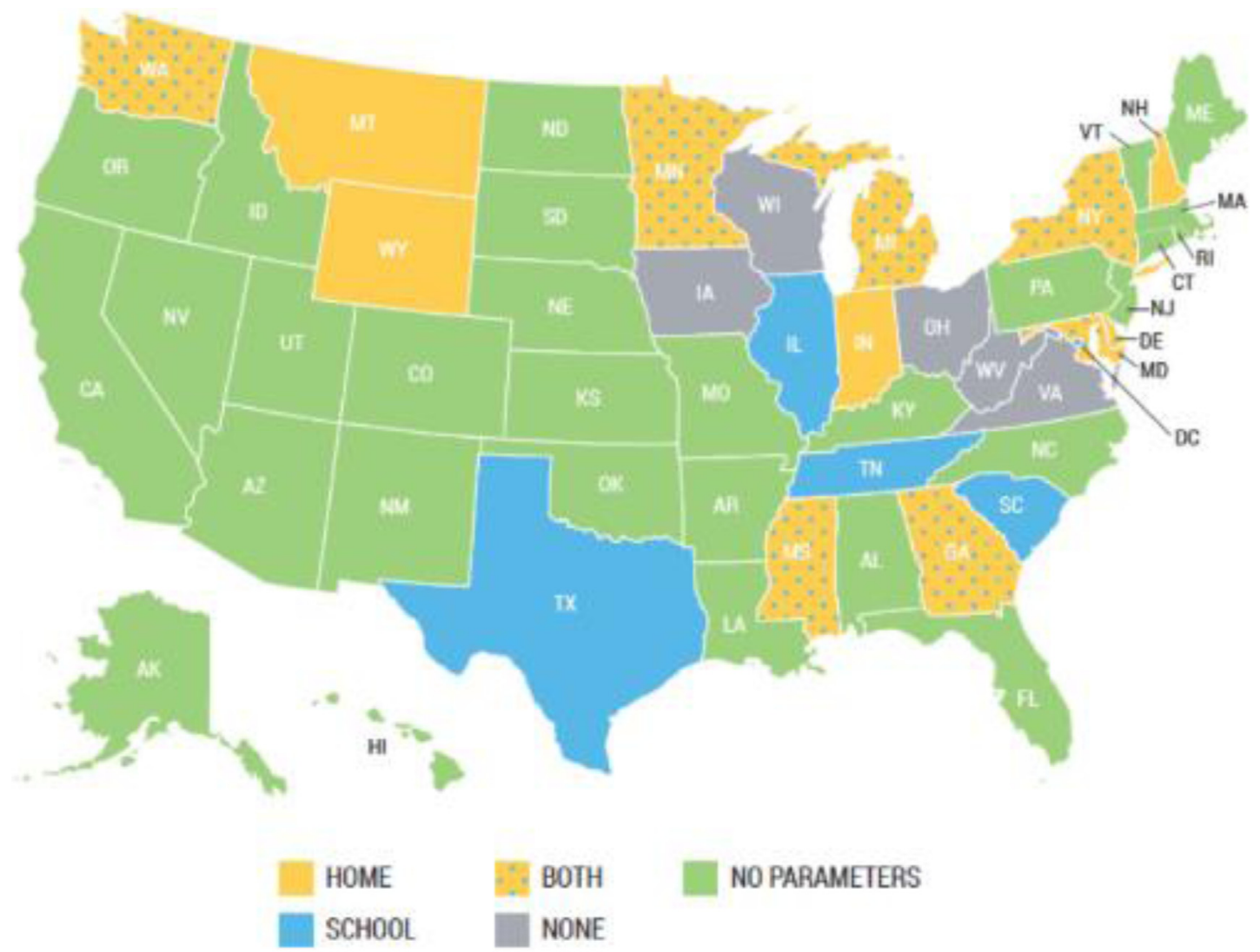

Fig. 2. Medicaid originating sites. (Courtesy of the Center for Connected Health Policy, Sacramento, CA; with permission.) 


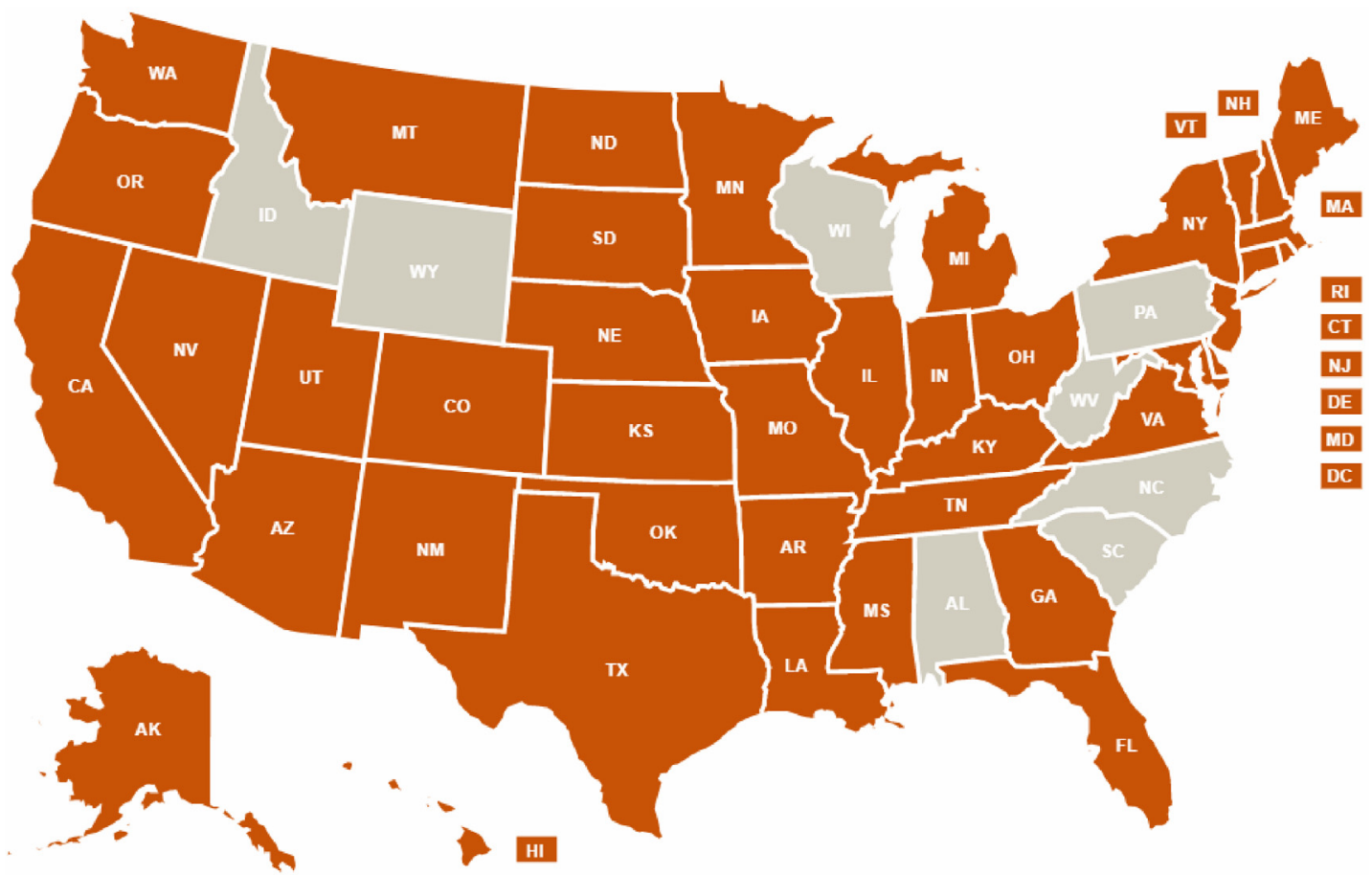

Policy Exists/Explicitly Allowed No Policy Exists or Not Explicitly Allowed

Fig. 3. Parity laws for commercial plans. (Courtesy of the Center for Connected Health Policy, Sacramento, CA; with permission.)

the state has a telehealth parity law, any of the private payors should cover telehealth services. However, these are policy dependent and need to be confirmed for specific situations. It is recommended that insurance verification is obtained before the visits.

Some private payers still follow the more restrictive Medicare policy on location of originating site (location of patient) New updates are in progress to ease these restrictions to allow delivery of care to patients from any location (ie, home or work).

Coding for these visits is similar to Medicare coding. Specific telehealth codes can be used and, for the E/M coding, the modifier GT is applicable. Reimbursement is usually at the standard rate for that CPT code according to the physician fee schedule with that payer.

As the benefits of telemedicine programs are becoming more evident, many of the commercial payors are expanding their policies.

\section{EMPLOYER-PAID PLANS}

Many companies that sponsor group health care plans are offering telemedicine as part of their coverage and this number is growing. ${ }^{26}$ Companies recognize the benefits, which include convenience, better access for chronic health conditions, reduced absenteeism, and reduced health care costs. There are some concerns whether employees will use these benefits. Further instruction may be needed to educate workers on which medical issues are amenable to telehealth services and when to present for immediate care. Additional training may be beneficial to show employees how to access the telemedicine platform, as well as how to submit claims.

The millennial generation is the fastest-growing segment of the work force. Millennials comprise $50 \%$ of the American workforce and are comfortable with embracing new technology. Telehealth that provides quick access to physicians, personal data, and opportunity to research diagnosis has a high level of acceptability in this demographic. ${ }^{27}$

Pricing structures vary across telemedicine provider models. Some employers provide the benefit at no extra charge for their employees. Others partner with telehealth providers that charge a consultation fee to the employee at the time of visit. These fees create a barrier to employees 
using the service. Because telemedicine can potentially save employers money (especially those that are self-funded) from averted visits to doctors' offices, urgent care facilities, and emergency rooms, employers need a plan that encourages their employees to use their telehealth platform. There is some debate whether these services will reduce the cost of health care or just add to it. ${ }^{28}$ This question will depend on the rate of use, and studies have shown clear cost savings of these programs. ${ }^{29}$

\section{SELF-PAY}

Thirty percent of telemedicine visits are paid out of pocket, according to a previous survey. This proportion compares with those who have visits covered by insurance $(11 \%)$ or employers $(10 \%) .{ }^{30}$

Telemedicine usage is most common among patients between 25 and 34 years of age; those more than 55 years of age are least likely to use telemedicine, according to a survey. However, more than half of those 55 years of age or older have accessed remote physician care through a phone call, which is considered a form of telehealth. Most of the patients surveyed, $76 \%$, say that access to health care is more important than in-person appointments. ${ }^{31}$

There are numerous telehealth companies and platforms that are marketing direct to consumers because patients are willing to pay for the convenience. With telehealth, individuals can be evaluated for a sleep disorder, have a home sleep study, review results, and start treatment within a shorter time than it takes to see a sleep medicine specialist locally. This model is gaining popularity, especially among patients with a previous diagnosis of obstructive sleep apnea who need a new positive pressure device. Pricing is completely determined by the various parties involved.

\section{SUMMARY}

Innovation in technology is redefining the world, including health care. Patients want convenient and quality interactions with their providers. The addition of telemedicine technologies and asynchronous provider-to-patient communications is creating a more connected model of health care that will improve access and the value of care while decreasing costs, as well as enabling patients to participate more directly in their own care. As new technologies and new models of care continue to emerge, providers need to continue to monitor the rapidly changing landscape of telemedicine coding and reimbursement.

\section{ADDENDUM}

On March 13, 2020, the CMS announced sweeping changes allowing increased flexibility in delivering safe and effective care during the COVID-19 pandemic. These temporary modifications were made to encourage the use of telemedicine and eased previous requirements (discussed earlier). These constructive changes permit providers to continue to care for patients across the country in a safe and effective manner. Most private payors have also followed suit. The following is a review of the guidelines at the time of this final submission.

- One of the most important shifts includes coverage for telehealth services furnished in any health care facility but now also including the patients' homes.

- Many states have temporarily relaxed licensure requirements related to physicians licensed in another state and retired or clinically inactive physicians.

- Medicare has relaxed the restrictions related to providing telehealth and virtual services to new patients. For the duration of the public health emergency, telehealth and virtual services can be provided to new and established patients. Patients must consent, which may be obtained before or at the time of service. Ensure that consent is documented in the patient's medical record.

- Telemedicine visits are paid at the same rate as in-person visits. During the COVID-19 crisis, Medicare will pay the nonfacility amount for telehealth services when they are billed with the POS the physician would have used if the service had been provided in person (eg, POS 11: office). Physicians should append modifier -95 to the claim lines delivered via telehealth.

- CMS announced it will pay for telephone E/M visits (CPT codes 99441-99443) at parity with office E/M codes. On an interim basis, the RVUs and payment amounts will align as follows: 99441 will align with 99212, 99442 will align with 99213, and 99443 will align with 99214.

- During the COVID-19 emergency, Medicare will cover continuous positive airway pressure devices based on clinical assessment of the patient.

The COVID-19 pandemic has abruptly shifted the way clinicians practice sleep medicine. Telemedicine is suddenly not only convenient but necessary. It is unclear what the future of telemedicine coding and reimbursement will be once the 
pandemic resolves. Will clinicians return to all the previous stringent regulations? Will CMS and private payors appreciate the potential cost savings and benefits to patients and allow these temporary revisions to continue? Clinicians will have to await the answers.

\section{DISCLOSURE}

The author has nothing to disclose.

\section{REFERENCES}

1. Economic Impact of obstructive sleep apnea. American Academy of Sleep Medicine - Association for Sleep Clinicians and Researchers. 2019. Available at: https://aasm.org/advocacy/initiatives/ economic-impact-obstructive-sleep-apnea/. Accessed December 2, 2019.

2. Wickwire EM, Vadlamani A, Tom SE, et al. Economic aspects of insomnia medication treatment among Medicare beneficiaries. Sleep 2019;43(1). https:// doi.org/10.1093/sleep/zsz192.

3. Wickwire EM, Tom SE, Vadlamani A, et al. Older adult US Medicare beneficiaries with untreated obstructive sleep apnea are heavier users of health care than matched control patients. J Clin Sleep Med 2020;16(1):81-9.

4. CMS. US health care spending to reach nearly $20 \%$ of GDP by 2025. Advisory Board Daily Briefing. Available at: https://www.advisory.com/dailybriefing/2017/02/16/spending-growth. Accessed November 24, 2019.

5. New findings Confirm predictions on physician shortage. AAMC. 2019. Available at: https://www. aamc.org/news-insights/press-releases/newfindings-confirm-predictions-physician-shortage. Accessed January 2, 2020.

6. Singh J, Badr MS, Diebert W, et al. American Academy of Sleep Medicine (AASM) position paper for the use of telemedicine for the diagnosis and treatment of sleep disorders. J Clin Sleep Med 2015; 11(10):1187-98.

7. Watson NF. Health care savings: the economic value of diagnostic and therapeutic care for obstructive sleep apnea. J Clin Sleep Med 2016;12(08):1075-7.

8. Cohen JK. The growth of telehealth: 20 things to know. Becker's Hospital Review. Available at: https:// www. beckershospitalreview.com/healthcareinformation-technology/the-growth-of-telehealth-20things-to-know.html. Accessed January 2, 2020.

9. CPT 2020 professional edition. Chicago: American Medical Association; 2019. CPT is a registered trademark of the American Medical Association.

10. mHealthIntelligence. Is there a difference between telemedicine and telehealth? mHealthlntelligence. 2019. Available at: https://www.mhealthintelligence. com/features/is-there-a-difference-between-tele medicine-and-telehealth. Accessed January 24, 2020.

11. National Consortium of Telehealth Research Centers. National Consortium of telehealth research Centers. Available at: https://www.telehealth resourcecenter.org/. Accessed December 2, 2019.

12. Telehealth Resource Centers (TRCs). Health Resources \& services administration 2019. Available at: https://www.hrsa.gov/rural-health/telehealth/ resource-centers. Accessed January 24, 2020.

13. CPT 2020. Professional edition. Chicago: American Medical Association; 2019.

14. Coders MBand. AMA Announces 2021 E/M changes. Medicalbillersandcoders. 2020. Available at: https://www.medicalbillersandcoders.com/blog/ ama-announces-2021-em-changes/. Accessed January 20, 2020.

15. AMA issues checklist for the transition to $E / M$ office visit changes. American Medical Association. 2019. Available at: https://www.ama-assn.org/press-center/ press-releases/ama-issues-checklist-transition-emoffice-visit-changes. Accessed January 30, 2020.

16. Tuckson RV, Edmunds M, Hodgkins ML. Telehealth. N Engl J Med 2017;377(16):1585-92.

17. Schatz Brian. Text - S.2741 - 116th Congress (20192020): creating Opportunities now for necessary and effective care technologies (CONNECT) for health Act of 2019. Congress.gov. 2019. Available at: https://www.congress.gov/bill/116th-congress/ senate-bill/2741/text. Accessed January 29, 2020.

18. Digital Medicine Payment Advisory Group. American Medical Association. Available at: https://www. ama-assn.org/practice-management/digital/digitalmedicine-payment-advisory-group.

Accessed December 2, 2019.

19. Request for addition. CMS. Available at: https:// www.cms.gov/Medicare/Medicare-GeneralInformation/Telehealth/Addition. Accessed January 24, 2020.

20. Medicare advantage. The Henry J. Kaiser Family Foundation; 2019. Available at: https://www.kff.org/ medicare/fact-sheet/medicare-advantage/. Accessed December 1,2019.

21. Press release CMS finalizes policies to bring innovative telehealth benefit to Medicare Advantage. CMS. Available at: https://www.cms.gov/newsroom/pressreleases/cms-finalizes-policies-bring-innovativetelehealth-benefit-medicare-advantage. Accessed January 24, 2020.

22. Medicaid home. Medicaid home. 2020. Available at: https://www. medicaid.gov/. Accessed January 20, 2020.

23. Center for connected health policy. Thumbnail. Available at: http://www.cchpca.org/. Accessed January 24, 2020.

24. Resources. ATA. Available at: https://www. americantelemed.org/resource/. Accessed January 30, 2020. 
25. Center for Connected Health Policy. Thumbnail. Available at: http://www.cchpca.org/. Accessed December 1, 2019.

26. The advantages of telehealth-powered employer Clinics. InTouch health. 2019. Available at: https:// intouchhealth.com/the-advantages-of-telehealthpowered-employer-clinics/. Accessed January 2, 2020.

27. Millennials demand telehealth in a move away from traditional primary care model. Healthcare IT News. 2018. Available at: https://www.healthcareitnews. com/news/millennials-demand-telehealth-moveaway-traditional-primary-care-model. Accessed January 30, 2020.

28. Licurse AM, Mehrotra A. The effect of telehealth on spending: thinking through the numbers. Annals of Internal medicine. 2018. Available at: https://annals. org/aim/article-abstract/2678087/effect-telehealthspending-thinking-through-numbers. Accessed January 24, 2020.

29. Michaud TL, Zhou J, Mccarthy MA, et al. Costs of home-based telemedicine programs: a systematic review. Int J Technol Assess Health Care 2018; 34(4):410-8.

30. 2019 employer health benefits survey - summary of findings. The Henry J. Kaiser Family Foundation; 2019. Available at: https://www.kff.org/reportsection/ehbs-2019-summary-of-findings/. Accessed January 26, 2020.

31. Vonk C. Telehealth trends to watch in 2020. GD - mobile telemedicine community paramedicine - general devices 2020. Available at: https://general-devices.com/ telehealth-trends-to-watch-in-2020. Accessed January 16, 2020. 